\title{
Advanced physical assessment skills: implementation of a module
}

\author{
Sharon Aldridge-Bent
}

Sharon Aldridge-Bent is a Senior Lecturer: Community Health Care Nursing, Faculty of Society and Health, Buckinghamshire

New University

Email: Sharon.Aldridge-Bent@bucks.ac.uk

$\Gamma$ he issue of long-term conditions (LTCs) has been at the top of the government's health agenda for many years. It is estimated that 15.5 million people in the UK have an LTC (Department of Health (DH), 2008). The cost of this presents as a phenomenal burden, as people with LTCs account for a large proportion of the NHS budget (Darzi, 2007).

The majority of district nurses would already identify the core of their work with older people with diseasespecific case management needs (Drennan and Goodman, 2004). The idea of a highly skilled clinician delivering this care was supported by the work of Mckenna and Keeney (2004), where it was also highlighted that a district nurse with additional skills and experience would have the most impact on the management of people with LTCs. The debate then is, can these additional skills be included in the current district nursing training to produce highly skilled nurses who have the ability to manage cases effectively in line with Government recommendations?

The challenge for educational institutions, therefore, is to provide learning programmes that address as many approaches as possible to case management in an imaginative and innovate way. This is even more pertinent when

\section{ABSTRACT}

This article aims to explore and examine advanced physical assessment skills and the role of the district nurse. It will particularly highlight district nurses' perceptions of how they may implement skills learnt on a new module introduced into the Community Health Care Nursing degree at a university in London. Physical assessment skills have traditionally been viewed as part of a doctor's role; however, with the advancement of nursing roles, it is argued that it has become a key nursing skill. As Government policy continues to expect health professionals to keep patients in the community who have complex health and social care needs, the role of the district nurse presents as 'best placed' to take on this challenge (Department of Health (DH), 2005a; 2005b).

Evaluation of the district nurses' perceptions of their practice is shared here, highlighting some of the challenges that they face. The article will address the complexity of developing a curriculum in response to the $\mathrm{DH}$ initiatives and the importance of listening to students on courses.

\section{KEY WORDS}

Advanced physical assessment • District nurse • Case management - Long-term conditions the clinical skills being taught require ongoing practice in the clinical area and opportunities for consolidation may be limited. This perception of application of skills is therefore the basis of this research.

\section{Literature review}

The body of knowledge around the case management of LTCs is still relatively new in the UK, with the majority of the systematic research emerging from the US. Therefore, policy within Britain is leaning towards Anglo-American approaches and models of care (Hudson, 2005). One American initiative introduced in the UK was the Evercare project funded by the $\mathrm{DH}$ which took place in several selected pilot sites in the UK. It concentrated on level three case management, and its overall aim was to target disease prevention and long-term care of older people that were of high risk of hospitalization (United Healthcare, 2005; Wilson, 2006). The main findings from this project are around whether or not the principles of case management are transferable from US care settings (King's Fund, 2006). Another example of case management in the UK is the Castlefields model that is run in general practice. While being hailed as a good example in relation to reduced unplanned hospital admissions in the older population, the model does not examine in any depth the role of district nurses in that care (ColinThorne and Belfield, 2004).

Although there have been several opinion papers written in recent months mainly in nursing journals (Pratt, 2006; Cook, 2008; Barrett et al, 2007), the agenda is moving so swiftly that 'keeping track' of changes poses a challenge for not only the policy writers but also the professionals and practitioners (Casey and Mackreth, 2007).

In view of the lack of published literature and evidence around the perceived outcomes of case management in primary care, and more specifically the role that the district nurse performs in physical assessment of patients with disease-specific unstable LTCs, this research attempts to examine one perspective in relation to the physical assessment module delivered and how the skills learnt by the district nurse will be applied in practice.

\section{The study}

The main reason for carrying out this research was to establish whether or not the implementation of a physi- 
cal assessment module into a Community Health Care Nursing- District Nurse university degree, would benefit the students on the course. This is not only in terms of their practice and service demands but also their academic and professional development. As an institution, there needs to be a shared understanding of workforce planning and requirements in a university in order to develop flexible student-centred learning.

\section{Method}

The research employed a qualitative exploratory approach Qualitative research was elected because to what degree district nurses apply physical assessment skills has to be answered by the individual, and to rely on quantitative data alone would not necessarily allow for the question to be answered (Silverman, 2005).

First, a focus group of ten district nurse students was employed as a pilot in order to ascertain certain attitudes (Gray, 2004) towards the management of LTCs in relation to district nursing practice. The entire district nurse student group was selected from the existing programme; they all had similar levels of educational attainment and length of time - spanning one to five years - working within the community setting as staff nurses. The themes from the focus group then assisted with the final construction and structure of the individual interviews. Three district nurse students were randomly selected irrespective of age, gender or background, and were interviewed in more depth before they undertook the module and three months after they had completed.

A structured method of data analysis was adopted using a 'thematic' approach (Parahoo, 2006). In the initial stage of the analysis the entire transcripts were read in order to get a sense of the whole. Once the data had been coded (Parahoo, 2006: Box 1) a seven-step procedure of analysis was used.

\section{Ethical approval}

Prior to the study being implemented, ethical approval was sought from the University ethics committee. Within the ethical approval application the researcher acknowledged the requirement to keep participants informed, and the issues of consent and confidentiality were paramount.

\section{Participants}

The population for this study was student district nurses from the Community Health Care degree course at a university in London. The cohort was embarking on the second semester of a one-year course.

\section{Findings and discussion Understanding of physical assessment}

The research provided a view of the participants' descriptions and understandings of physical assessment. Here, it was evident that views were opposing and the perspectives could be categorized into two strands, one where they took limited responsibility for the outcome of the physi- cal assessment and the other where they felt they would. Some thought clearly that physical assessment was to be able to perform a 'top-to-toe' physical examination and take a medical history (Morgan, 2005). They thought that this information was then reported back to the GP for a diagnosis. Others identified the actual skills involved (e.g. inspection, palpation and percussion) and the ability to perform the skills competently and diagnose accordingly. Throughout, all participants expressed concerns in relation to competence and how to maintain it.

The ability to differentiate 'normal' from 'deviations of the abnormal' provoked some interesting findings. All participants stated that the types of patients they cared for had at least one LTC, if not multiple, and that they rarely came across 'normal' patients. The main consensus within the research was that they did not feel that it was part of their role to make a specific diagnosis or differential diagnosis, and that such a perspective was in conflict with the nursing role (Baid, 2006):

'everyone has a different idea as to what it is ... particularly within the nursing professions, I think - for example, DNs have a different idea to practice nurses, practice nurses to acute nurses, etc (Participant 3; Interview 3)

\section{'From what I understand - and I'm a bit confused about it all - we do physically assess patients already; when we go in, we do an advanced assess- ment. To me this is something that a doctor would do.'(Participant 4; Focus Group 1)}

\section{Role definition}

The role of the district nurse has been under scrutiny (Edwards and Dyson, 2003; Queen's Nursing Institute, 2006) with many district nurses experiencing deficits in knowledge and skills, particularly in relation to physical assessment. Some participants felt that they were well placed to take on physical assessment and saw it as an extension of their existing role, whereas others were less optimistic and saw the expansion of their role as signalling

Box 1. Colaizzi's procedural steps of data analysis

- Data transcribed verbatim, and then re-read

- Significant statements relevant to the experience extracted

- Meanings formulated

- Relevant statements organized into themes

- Themes utilised to present a full description of the experience

- The researcher will then return to the description and its original source for the confirmation of validity

Adapted from Colaizzi (1978) as cited in Parahoo (2006) 
a move to devolve nursing care to health-care assistants and the demise of professional nursing (Wheeldon, 2005).

This debate between what constitutes role expansion as opposed to role extension is evident in almost every area of this discussion. In role expansion the nurses develop in order to function more effectively within their role. Alternatively, role extension is when skills or tasks previously the responsibility of another professional are adopted (Kennedy, 2004; Wheeldon, 2005):

'if I am spending all my time doing physical assessment, then I am not doing my nursing, and how will I divide that time? I feel that physical assessment is not part of the nursing role. I don't think I would have personally chosen the physical assessment part of the role.' (Participant 1; Interview 4)

In their responses, the participants all expressed concerns around district nursing losing sight of its central core values (Scott, 1999). The growing haziness where nursing stops and medicine begins was highlighted; however, there was an awareness among the participants that the government wishes to remove demarcation of roles, with a service that is organized around the patient rather than professional roles (Scott, 1999). One participant's perspective was that by taking on physical assessment skills - traditionally the domain of doctors - she was in fact developing her practice to give effective nursing care, as she felt she was able to give more holistic care as a result:

'I personally think we should push ourselves forward, and I think we should gain all the skills we can.' (Participant 2; Interview 2)

\section{Professional perspectives}

An additional perspective to district nursing practice is the pending authorization of the Nursing and Midwifery Council (NMC) standards for advanced practice:

'Advanced nurse practitioners are highly experienced and educated members of the care team who are able to diagnose and treat your health care needs or refer you to an appropriate specialist if needed.' (NMC 2005 pg: 4)

This will have an impact upon whether or not the role of the district nurse will in fact fall clearly into the standards criteria. The University-validated course has already been mapped against the standards as a precaution, although there will have to be further debate around the NMC suggestion that advanced practice level of 'expert knowledge' would be master's-level thinking (Casey and Mackreth, 2007). If this is to be the case, at present it may mean that closer links would have to be made for accreditation of prior learning and bridging programmes to support portfolio development at master's level.

\section{Physical assessment Implementation}

All participants commented upon the speed in which physical assessment was to be introduced into their role and the clinical setting. There was a sense that the whole thing felt somewhat rushed and that there was a distinct lack of planning when it came to certain aspects of its implementation. This point was highlighted by Rushforth and Glasper (1999) when stating that nursing must be proactive not reactive when addressing future health-care demands, and that nurses needed to feel part of the development of the change.

All had reported difficulties when it came to accessing equipment in order to practice. Some had even had to purchase their own. This was viewed by some as the level of commitment and priority that the trusts gave to the implementation of physical assessment in district nursing practice.

'I am not sure that there will be enough time to do physical - the pressure will be on us to function in the normal way. Sometimes it's hard enough when doing the normal assessment - let alone a PA on top of it! We also have no equipment - they are expecting us to learn these skills with no equipment!' (Participant 1; Interview 4)

When it came to appropriate supervision and mentorship, the support was sporadic among the group. The main concern was that there were not enough qualified physical assessors in the clinical setting, and at times they felt forced to practice in the absence of a suitable competent peer (Worth, 2001). The participants highlighted that their community practice teachers (CPTs) were reluctant to support them as they themselves were untrained in such skills:

'it would have been very useful if we were allocated a mentor with the physical assessment qualification, because I am struggling to find someone. I could go and sit with a GP but they don't do physical assessment. I need somebody who is going to do it from my point of view out in the community, so I am really struggling to find somebody at the moment.' (Participant 5; Focus Group 1)

The participants highlighted concerns that different Trusts were commissioning different university courses for physical assessment, and some were doing 'in-house' training in order to acquire the skills. In light of all the developments and mechanisms for monitoring practice - e.g. clinical governance, audit, risk management and clinical practice - benchmarking this 'ad hoc' way of implementing physical assessment would have great impact on such developments (QNI, 2006):

'out in our area they have all done different courses - some did a seven-day in-house course, 
some have done it at other institutions and some here - all with different outcomes. But to the Trust they have just done physical assessment - it ticks a box.' (Participant 1; Interview 4)

\section{Education}

\section{Expectations of the module}

An interesting feature was the participants' level of anxiety in anticipation of the module. They cited fears of how intense the learning may become and the amount of new information they would have to absorb. These factors would inevitably affect their learning or their ability to learn. Hinchliff (2001) suggests that this 'self concept' will influence the approach to learning and impinge upon the teaching and learning process. Benner (1994) also enforces this, saying that 'capturing' a person's readiness to learn forms a key feature of effective teaching. This degree of anxiety was perhaps underestimated and went on to manifest in patterns of behaviour by the group throughout the delivery of the module:

'I am quite anxious about this module; to be quite honest, it does look like a lot to put into a district nursing degree course. I think it should not necessarily stand alone and you need to do further underpinning knowledge before attempting to do this, especially from a community practitioner's point of view.' (Participant 4; Focus Group 1)

\section{Module preparation}

The participants all agreed that it was imperative that anatomy and physiology were huge aspects of the module; however, they felt there was an assumption that they should come with this knowledge. Most felt that the last time they had done anatomy was in their pre-registration nursing. They all accepted that they required more on anatomy, physiology and patho-physiology as fundamental to the module (Rushforth et al, 1998). This highlighted that the students' educational needs were not considered at the start of the module, and that this had caused some participants considerable anxiety (Hudson and Moore, 2006).

\section{Module delivery}

The team delivering the module were from the Acute and Continuing Care School; this did appear to have some influence on the perspective of the module. The participants felt that the focus was mainly acute and that there was no acknowledgment of their previous experience to build up on in order to extend understanding. They all felt that they brought extensive communication skills in relation to holistic patient assessment in the community setting.

\section{Perceptions of practice}

The findings demonstrated that the participants perceived that they had acquired a variety and range of knowledge and skills as a result of this module; however, they also identified some anomalies when it came to whether or not they would be able to use these skills in their day-today practice.

All participants agreed that their knowledge base was much improved having studied the module. They particularly found the informal sharing of information and knowledge invaluable. Most felt that they could perhaps use certain aspects of the skills learnt, if not all of them. This suggests, perhaps, the question of: what physical assessment skills do nurses need in order to practise nursing, if only certain aspects of physical assessment in reality are being used? (Lesa and Dixon, 2007)

'As it stands at the moment, unless I initiate it myself, I don't think it will be used - unless I push it! However, in the future when they start bringing in unregulated stuff, everyone seems to be moving up a peg and they are asking GPs and Nurses to do more - I think it is something we may need in the future.' (Participant 2; Interview 5)

\section{Recommendations Clearer definitions}

There is a need for clarification around the definition of physical assessment in relation to nursing practice (Carnwell et al, 2003). This should incorporate definitions of district nursing and whether or not the role is to be aligned with and identified as advanced practice. This direction could come from the NMC and would be pivotal in moving forward innovations in district nursing. This would also assist district nurses in developing more autonomously and expanding their role, rather than extending their role to become mini doctors (Aranda and Jones, 2008).

\section{Education}

The lessons for nurse education have been invaluable, and an in-depth examination of the approach to the module was undertaken and changes were identified:

- The respondents felt that they required more information about the module earlier on in the course. The module leader now attends the course induction week to introduce the module and give an overview of the learning involved

- An anatomy and physiology workbook has been devised and is distributed to the students to establish prior learning and work towards the baseline knowledge required for the module.

- A site evaluation form was devised and circulated to the students, so that they are able to identify learning opportunities and equipment in their practice placement areas. It also advises the students of the need to identify a mentor or supervisor in practice to assess skills learnt. While the above changes have not formally been evaluated, it is in the author's opinion that subsequent students embarking upon the physical assessment module present as less anxious than the original cohort studied. The team 
delivering the module have acknowledged these students' previous experience and have endeavoured to continue to meet their needs.

One question that has arisen is whether the physical assessment module should be taught within the Community Health Care Nursing course. It is the author's recommendation based on the findings that this module should be offered as a stand-alone module for experienced district nurses that have established themselves within their role (DH, 2007). It is also recommended that the module be re-developed and designed to be a work-based learning module (Winterburn and Lodge, 2004). This would allow for a style that recognizes the existing expertise of the students, allowing for new skills to be taught, and most importantly consolidated, in the practice setting (Casey and Mackreth, 2007).

\section{Areas for further research}

It is clear that there needs to be a wider evidence base when it comes to the role expansion of district nurses to perform physical assessment. At present, there is limited research into the impact of role transition on patient care (Rushforth and Glasper 1999), Roland and Boaden 2007), and the efficacy of physical assessment training is inconclusive (Wheeldon, 2005). For this reason, it is recommended that a combination of qualitative and quantitative research is undertaken.

\section{Conclusion}

Primary health-care practice is in a state of change, resulting in new and expanding roles in the community. This discussion has revealed that, in order for district nurses to embrace physical assessment within their role, they have to view it as relevant to their practice. This relevance will only become clear as the government's agenda for long-term conditions and case management is implemented. Higher education institutions need to understand and collaborate with workforce planners in order to respond effectively to these changes and develop curriculum and education programmes to assist professionals in supporting people with long-term conditions (Casey and Mackreth, 2007). BJCN

Aranda K, Jones A (2008) Exploring new advanced practice roles in community nursing: a critique. Nursing Inquiry 15(1): 3-10

Baid H (2006) Differential diagnosis in advanced nursing practice. Journal of Nursing 15(18): 1007-11

Barrett A, Latham D, Levermore J (2007) Part 3 Defining the unique role of the specialist district nurse practitioner British Journal of Community Nursing 12(12): $566-70$

\section{KEY POINTS}

- There is a need for clarification around the definition of physical assessment in relation to district nursing practice.

- There is a need for the Nursing and Midwifery Council to provide guidance, in the form of standards, for advanced practitioners working in the community.

- Higher education institutions are under increasing pressure to provide programmes that address changes in service delivery and workforce development.
Benner P (1994) From Novice to Expert: excellence and power in clinical nursing practice. Addison-Wesley California

Carnwell R, Daly E, William M (2003) Advanced nursing practitioners in primary care settings: and exploration of the developing roles. Journal of Clinical Nursing 12(5): 630-42

Casey D, Mackreth P (2007) Developing education for long term conditions management. British Journal of Community Nursing 12(1): 19-22

Cave I (2005) Nurse Teachers in higher education - without clinical competence, do they have a future? Nurse Education Today 25: 646-51

Colin-Thorne D, Belfield G (2004) Improving Chronic Disease Management $\mathrm{DH}$, London

Cook R (2008) QNI seek clarity over the future of the specialist practitioner role. British Journal of Community Nursing 11(6): 241

Darzi A (2007) Healthcare for London: a framework for action. NHS, London

Department of Health (2005a) National Service Framework for Long Term Conditions. DH, London

Department of Health (2005b) Supporting People with Long Term Conditions: An NHS and Social Care Model to support local innovation and integration. $\mathrm{DH}$, London

Department of Health (2007) Towards a Framework for Post Registration Nursing Careers- Consultation document. DH, London

Department of Health (2008) Raising the Profile of Long Term Conditions Care: A compendium of Information. DH, London

Dewey J (1938) Experience and Education. The Macmillan Company, New York

Drennan V, Goodman C (2004) Nurse-led case management for older people with long term conditions. British Journal of Community Nursing 9(12): 527-33

Edwards M, Dyson L (2003) Is the district nursing service in a position to deliver intermediate care? A national survey of district nursing provision Primary Health Care Research and Development 4: 353-64

Gray D (2004) Doing research in the real world. Sage, London

Hinchliff S (2001) The Practitioner as Teacher. Bailliere Tindall, London

Hudson B (2005) Sea change or quick fix? Policy for long term conditions in England. Journal of Health and Social Care in the Community 13 (4): 378-85

Hudson AJ, Moore LJ (2006) A new way of caring for older people in the community. Nursing Standard 20(46): 41-7

Kennedy C (2004) A typology of knowledge for district nursing assessment practice. Journal of Advanced Nursing 45(4): 401-9

King's Fund (2006) Combined Predictive Model King's Fund Publications London

Lesa R, Dixon A (2007) Physical Assessment: implications for nurse educators and nursing practice. International Nursing Review 54: 166-72

McKenna H, Keeney S (2004) Community nursing; health professional and public perceptions. Journal of Advanced Nursing 48(1): 17-25

Morgan M (2005) New Opportunities for district nursing: chronic disease and matrons. British Journal of Community Nursing 10(1): 6-7

Nursing and Midwifery Council (2008) The Code: Standards of conduct, performance and ethics for nurses and midwives. NMC, London

Parahoo K (2006) Nursing Research: Principles, Process and Issues. Palgrave Macmillian, Hampshire

Pratt L (2006) Long term conditions 5: meeting the needs of highly complex patients. British Journal of Community Nursing 11(6): 234-40

Queen's Nursing Institute (2006) Vision and Values: a call for action on Community Nursing: QNI London

Roland M, Boaden R (2007) Admissable evidence Health Service Journal 1: $60-1$

Rushforth H, Warner J, Burge D, Glasper E (1998) Nursing physical assessment skills: implications for UK practice. British Journal of Nursing 7(16): 968-72

Rushforth H and Glasper E (1999) Implications of nursing role expansion for professional practice. British Journal of Nursing 8(22): 1507-14

Scott H (1999) Nurses must not become substitute doctors British Journal of Nursing 8(22): 476

Silverman D (2005) Doing Qualitative Research. Sage, London

United Healthcare (2005) Assessment of the Evercare Programme in England 2003-2004 Executive Summary

Wheeldon A (2005) Exploring nursing roles: using physical assessment in the respiratory unit. British Journal of Nursing 14(10): 571-5

Wilson P (2006) Long term conditions: making sense of the current policy agenda. British Journal of Community Nursing 10(1): 544-51

Winterburn S and Lodge E (2004) Preparing nurses for 'first contact' in the management of minor illness. Journal of Community Nursing 18(9): 3-8

Worth A (2001) Assessment of the needs of older people by district nurses and social workers: a changing culture? Journal of Interprofessional Care 15(3): 257-66 